Instructions for authors, subscriptions and further details:

http://brac.hipatiapress.com

\title{
Escultura Sonora Baschet: Universal Design, Pedagogía e Inclusión
}

Martí Ruiz ${ }^{1}$ \& Robert Ruiz ${ }^{2}$

1) Universitat de Barcelona (UB), España.

2) Universitat de Vic (UVIC), España.

Date of publication: June 3rd, 2013

To cite this article: Ruiz, M., Ruiz i Bel, R. (2013). Escultura Sonora Baschet: Universal Design, Pedagogía e Inclusión. BRAC. Barcelona, Research, Art, Creation, 1(1), 62-99. doi: 10.4471/brac.2013.03.

To link this article: http://dx.doi.org/10.4471/brac.2013.03

\section{PLEASE SCROLL DOWN FOR ARTICLE}

The terms and conditions of use are related to the Open Journal System and to Creative Commons Non-Commercial and Non-Derivative License. 


\section{Baschet's Sound Sculpture: Universal Design, Pedagogy and Inclusion}

Martí Ruiz

Universitat de Barcelona
Robert Ruiz

Universitat de Vic

\section{Abstract}

This paper presents an approach to the Pedagogical Baschet Instrumentarium from the point of view of the Universal Design proposed by Ron Mace. This unprecedented double reading of the principles, applications and implications, draws a promising path that is based on over 60 years of evolution of Baschet Soundsculpture and currently appears as a oparadigm for contemporary reflection on pedagogy and the social function of art.

Keywords: sound sculpture, Baschet, universal design, acoustics, pedagogy. 


\section{Escultura Sonora Baschet: Universal Design, Pedagogía e Inclusión}

Martí Ruiz \& Robert Ruiz

Universitat de Vic

\section{Resumen}

El presente artículo presenta una aproximación al Instrumentarium Pedagógico Baschet des del punto de vista del que Universal Design propuesto por Ron Mace. Esta doble lectura inédita de los principios, aplicaciones e implicaciones, dibuja una trayectoria prometedora que se sustenta en más de 60 años de evolución de la Escultura Sonora Baschet y que actualmente se muestra como un paradigma para la reflexión contemporánea sobre la pedagogía y la función social del arte.

Palabras claves: escultura sonora, Baschet, diseño universal, acústica, pedagogía. 
D $\mathrm{n}$ el presente artículo se plantea un conjunto de reflexiones sobre las dimensiones participativas de la escultura sonora Baschet y sus posibles vínculos con el Universal Design (UD) o "Diseño para todos" en nuestros términos, y el Universal Design for Learning -UDL - (Diseño Universal para el Aprendizaje) con diferentes propósitos.

Nuestro propósito de mayor amplitud es estimar hasta que punto la identificación de estos vínculos podría servir eventualmente para interpretar las aportaciones de Baschet desarrolladas hasta el momento presente y para, en su caso, orientar algunos posibles nuevos desarrollos a partir de esos enfoques.

Estos propósitos se complementan necesariamente con reflexiones de carácter más general dado que lo que abordamos constituye uno de los ejemplos de sinergia mas evidente y logrado entre los ámbitos de la pedagogía y el arte, un caso paradigmático para reflexionar sobre las relaciones entre la cultura, las ciencias, las artes, y la educación: la Escultura Sonora Baschet y su dimensión participativa. Aunque la obra de los Hermanos Baschet es reconocida mundialmente, con una carrera que hoy en día cumple con sesenta años de actividad, sigue siendo necesario divulgar y profundizar en sus principios. En el presente artículo reflexionamos sobre el Instrumentarium Pedagógico y su proximidad con los principios del Universal Design propuestos por Ron Mace. Presentaremos brevemente ambos mundos, puesto que a menudo las personas especializadas o interesadas en unos de estos ámbitos puede desconocer el otro, así como pensamos que todo lo que sea tender puentes entre artistas y pedagogos es necesario y enriquecedor para todos. Escribimos este artículo desde posición de investigadores, docentes, alumnos, artistas y ciudadanos, y las cuestiones que planteamos en el presente son recurrentes, inevitables y compartidas con todo tipo de personas en nuestro contexto social actual. Esperamos pues que sea de interés para todos. Hay mucha información relativa a los dos ámbitos que queremos comparar, así que no pretendemos aquí describir totalmente, ni profundizar en las ideas y las tareas llevadas a cabo por los Baschet ni por Mace y sus colaboradores, ni todo lo que significa 
hoy en día el UD. Mencionaremos lo que consideramos esencial para proceder al desarrollo de la pequeña tesis del artículo.

Desde el Laboratori d'Art Sonor del Departament d'Escultura de la Facultat de Belles Arts de la UB, tenemos la fortuna de trabajar en la actualidad con François Baschet y hemos compartido horas de conversaciones con Bernard Baschet. Por ello nuestra experiencia directa con su trabajo puede ofrecer una perspectiva personal que privilegiada para la consecución de los intenciones planteadas tanto por los Hermanos Baschet como por las ideas que motivan el Universal Design.

Para dar forma a este ensayo hemos contado, pues, con esta "inmersión" personal en las actividades y las premisas inclusivas que los Baschet propusieron, con anterioridad a la formulación los principios del Universal Design, y con la colaboración de los investigadores de la línea en Universal Design del "Grup de Recerca en Atenció a la Diversitat" (GRAD) coordinada por el Dr. Ruiz de la UVic.

Actualmente, en 2013, Bernard y François Baschet tienen noventa y cinco y noventa y tres años respectivamente. Cuando conocimos a François y descubrimos asombrados que estaba dispuesto a comunicarnos, a legarnos metafóricamente su patrimonio intelectual, -como había venido haciendo durante décadas a través de exposiciones y publicaciones-, y a los pocos meses a estar trabajando conjuntamente en un taller en la Facultad de Bellas Artes, empezamos a entender que una especial mezcla de arte y ciencia le habían dado una perspectiva del trabajo en equipo, del valor transmisión y la transformación de los conocimientos digna de su legendaria fama de artista poco corriente, humilde maestro poliédrico. Sus ideas sobre la participación y la función social del arte nos han cautivado, han reforzando intuiciones que ya nos habían puesto en una senda que nos llevaba hasta él y nos proyecta hacia un futuro conjunto. Así pues, puede que el entusiasmo algo soñador que tiñen estas líneas proceda directamente del maestro Baschet. Tanto François como nosotros consideramos que es una suerte que finalmente una Universidad pueda acoger sus planteamientos.

Sesenta años de trabajo reconocido mundialmente no merecen sino el mayor de nuestros esfuerzos y agradecimiento, por la oportunidad de aprender de su trabajo como obra extensa y abierta, oportunidad de desarrollar las ideas y aplicaciones que sean más convenientes para las 
próximas generaciones.

Visto desde nuestra propia perspectiva, y la de los hermanos Baschet, el conocimiento científico -su método y su curiosidad no dogmática-, es inseparable del conocimiento intuitivo, y su plasmación creativa, sus aplicaciones, no tienen sentido sin encauzarse en distintos modos de transmisión y pedagogía. Se trata de la intención, la necesidad evolutiva, de compartir los hallazgos con el máximo número posible de personas. $\mathrm{Su}$ historia dibuja un horizonte prometedor, una ventana abierta de posibilidades para una educación y una participación cívica renovadas. Planteamientos como los propuestos por pensadores como Sir. Ken Robinson, -según los cuales la educación debe servir para que cada persona descubra sus capacidades y su potencial creativo y lo pueda cultivar-, parecen estar hoy en día en auge. Aunque no entraremos en profundidad sobre ello, esta perspectiva parece algo más posible gracias a ejemplos como el de los hermanos Baschet.

\section{Breve reseña histórica de la Escultura Sonora Baschet}

La historia de la obra y las ideas los hermanos Baschet está explicada en numerosas publicaciones, destacando entre ellas el espléndido libro escrito por el mismo François Baschet "Les structures Sonores, The SoundSculptures of Bernard and François Baschet" (Baschet, F., 1999). Dado que este libro se encuentra descatalogado y actualmente es complicado de encontrar en el Estado Español, a continuación relataremos los principales hechos y hallazgos, los más destacables para la comprensión del argumento del presente artículo. Evidentemente recomendamos encarecidamente el visionado de los sucesivos documentales sobre Baschet de Jacques Barzac, Eric Marin y Rudolf Ingo, lamentablemente también inéditos en el Estado Español.

La Escultura Sonora constituye hoy en día una parte importante dentro del amplio mundo del Arte Sonoro. Pero durante la primera mitad del siglo XX, y a lo largo de la segunda mitad, numerosas prácticas experimentales, periféricas, alternativas, desde el campo de la música, la poesía y las artes plásticas fueron conformando atomizadamente un marco que hoy podemos conceptualizar gracias a numerosos estudios, revisiones críticas interdisciplinarias, como las enciclopédicas publicaciones La mosca tras la oreja de Llorenç Barber 
y Sound Art de Alan Licht.

Evidentemente este no es lugar para esbozar tan vasto y generalmente desconocido universo, por lo que animamos al lector neófito a buscar entre las innumerables fuentes: libros, artículos, seminarios, documentales, webs, discos, etc. Aun así, desearíamos apuntar algunas relaciones con otras líneas y artistas sonoros para enmarcar mejor la obra Baschet, entender porqué se les considera como los padres -o por lo menos indiscutibles fundadores- de esto que llamamos Escultura Sonora, y así destacar la singularidad y el valor de su posicionamiento social.

Elegimos para ello el ejemplo de dos artistas - Bertoia, Partchcoetáneos a Baschet, con quien coincidieron en varias ocasiones, y veamos sumariamente hacia donde apuntan sus visiones coincidentes en algunos aspectos pero divergentes en otros.

El escultor Harry Bertoia desarrolló una obra característica y muy reconocible trabajando como Baschet con medios acústicos. Todas sus piezas sonoras muestran una línea de investigación centrada en un tipo de forma y material: Racimos de barras metálicas paralelas soldadas a una base, como grandes cepillos estilizados, o columnas de juncos flexibles, que suenan al chocar y frotarse las unas contra las otras. Cada pieza, cada grupo de barras, tiene un potencial tímbrico y una cadencia rítmica, una marcada dimensión táctil y una limitada posibilidad de control una vez la estructura empieza a moverse. Todas sus piezas sonoras se comportan de algún modo como autómatas cuando son percutidas o empujadas, hasta que la inercia cesa por sí misma. El sentido espacial y de conjunto escultórico -donde varias de las piezas pueden estar activadas simultáneamente- lo acerca a la noción de instalación ambiental y fundamentalmente a lo que llamamos arte sonoro. Probablemente mucha gente negaría a esos sonidos la categoría de música, en gran parte por presentarse siempre en contextos escultóricos y no darle usos ligados a las intenciones, liturgias y escenificaciones musicales. A lo sumo, desde una posición favorable a la lógica difusa podríamos asociar esos fenómenos sonoros a una concepción de la música muy contemplativa, paisajista, azarosa y desvinculada de las tradiciones musicales occidentales. Así pues, podemos ver en este compañero de exposiciones de Baschet, un extremo de la escultura sonora física e interactiva, pero que no pretende ser más 
instrumento de lo que es como escultura, ni buscar versatilidades musicales.

Desde el ámbito de la música contemporánea, el gran Harry Partch, ha sido en ocasiones propuesto como contrapunto a Baschet, como constructor de objetos sonoros experimentales. Sus creaciones, singulares y atractivas, exploran muchas familias de instrumentos distintos -percusión, cuerda, viento, voz-, para explorar dimensiones tímbricas, afinaciones alternativas microtonales, espaciales y gestuales. Aun así, y sin menospreciar en modo alguno el aspecto escultórico de los instrumentos de Partch ni sus concepciones musicales, hay que recordar que él mismo insistía cándidamente en que todo este abanico de desarrollos constructivos y tonales constituyen una solución a medida de sus necesidades e inquietudes musicales. Partch hacía mucho hincapié en que no esperaba que nadie excepto sus colaboradores tuviera que utilizar ni desarrollar los instrumentos ni los sistemas tonales que inventó. Más bien se trataba de dar un ejemplo fehaciente y estimulante de la posibilidad que cada uno se construya su propio conjunto sonoro. Podemos considerar que en este aspecto coincide con François Baschet, pero divergen en el sentido que éste se esfuerza a disponer todos sus conocimientos para animar a que otras personas los desarrollen -tanto en el campo instrumental como en el de la escultura-, y se dedica a crear una variadísima gama de objetos sonoros pensados para que los pueda tocar todo el mundo.

Veamos donde están las bases históricas y conceptuales que permitieron a los hermanos Baschet desarrollar tales propuestas. Después de participar activamente en la resistencia francesa durante la segunda Guerra Mundial, se dedicaron al estudio concienzudo de todas las fuentes históricas disponibles sobre teoría acústica, desde los clásicos griegos a Chadlni, Rayleight, Bouasse, y de todo lo que se relacionara con la organología. Y se dedicaron a la tarea de aplicar los conocimientos que adquirían a un nuevo tipo de objeto sonoro, uniendo los mundos de la física acústica, de la música y de la escultura. Modelando forma y sonido fueron pioneros de lo que ellos mismos bautizaron como "Escultura Sonora", y que constituyó un gran impulso para lo que posteriormente hemos llamado Arte Sonoro.

Estos inicios se dieron en el contexto, y con una sensibilidad semejante a los posicionamientos de escucha propuestos des del mundo 
de la música electroacústica, el trabajo con los sonidos del paisaje sonoro y las concepciones experimentales y otras nuevas ideas de después de las vanguardias de la primera mitad del siglo XX. Bernard Baschet trabajó con Pierre Shaffer en el Groupe de Recherches Musicales de París en el "Tratado el Objeto Sonoro" (Shaffer, P., 1966). La avidez de esa época hacia nuevas sonoridades y nuevas maneras de concebir la música, se manifestó en los hermanos Baschet en la búsqueda de las posibilidades de lo acústico, palpable y realizable de manera instrumental. Desde 1954 hasta hoy en día, han consolidado determinadas configuraciones y aplicaciones, para usos y usuarios, o intérpretes, que fueron evolucionando en función de las necesidades que ellos mismos observaban como artistas y fruto de colaboraciones con músicos y compositores.

Su novedoso enfoque para la comprensión de la física acústica, de los agentes y procesos involucrados, las capacidades y las combinaciones posibles entre estos elementos- aportan una comprensión singular de los instrumentos conocidos y los sonidos producidos, y los que todavía están por inventar. Una comprensión con una combinatoria abierta tanto por el lado de la física hipotética y posible, como por el lado de la interacción musical como hecho comunicativo, social. Hoy en día, estas concepciones -modulares, fractales, rizomáticas- todavía no se han agotado tras sesenta años de investigación, desarrollo y aplicación.

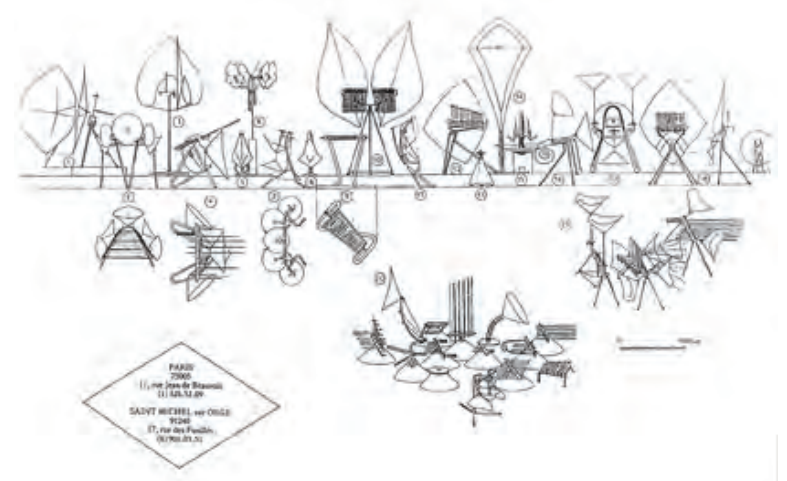

Figure 1. Dibujo de los hermanos Baschet. Por catalogar. 


\section{Martí Ruiz \& Robert Ruiz - Escultura Sonora Baschet}

Muchas de ellas se pueden considerar percusiones, desde idiófonos innovadores, a estructuras complejas que exploran todo tipo de registros y texturas sonoras, percusiones multitímbricas, melódicas, accesorios modulares para añadir resonancias y reverberaciones. La idea de inventar aplicaciones para transmitir las vibraciones internas de los materiales al aire, encontramos una gran variedad de formas con un enfoque escultórico del trabajo en metal, cartones y fibras, para la construcción de difusores en infinitas variaciones formales, planchas tensadas, plegadas, torsionadas, recortadas, cónicas, que modulan el sonido a la vez que lo hacen audible. Estos difusores característicos se unen a otros sistemas acústicos de altavoces inflables, cilindros y tubos plegables.

Para resumir el abanico de aplicaciones puestas en juego por las ESB mencionaremos la existencia de las variaciones recombinadas de los principios de pianos y teclados, cuerdas -guitarras, violines, violoncelos, contrabajos, salterios, arcos y slides-steel, arpas- e incluso instrumentos de viento. Destacan innovaciones como resonadores acústicos para la voz -familia de la Tôle à Voix- así como el trabajo también extenso de molinos y fuentes sonoras, estructuras que pueden combinar la participación, con automatismos físicos eólicos e hidráulicos, que abren otra vía de aproximación hacia el arte ambiental.

Especialmente las piezas pensadas en términos más instrumentales permiten la interpretación de de todo tipo músicas: arreglos de composiciones conocidas o tradicionales, así como nuevas músicas compuestas o improvisadas y experimentales. En numerosos casos para películas, en colaboraciones con artistas como Jean Cocteau, Alexander Calder y Toru Takemitsu.

Los hermanos Baschet han esbozado una clasificación de su propia obra en: Esculturas, Instrumentos, Estructuras y elementos pedagógicos. Aun así, en sus textos y hablando con ellos, nos insisten que se trata de una clasificación aproximada en base a la función o emplazamiento que se le dé a un objeto, y la casi totalidad de sus creaciones puede asumir cualesquiera de estas cuatro funciones.

Habitualmente han rehusado establecer estrictamente esta clasificación, dado que precisamente han intentado borrar dichas fronteras conceptuales. A causa de esta naturaleza múltiple en numerosas ocasiones los Baschet han tenido que luchar para que sus 
creaciones fueran aceptadas como instrumentos en contextos musicales y como esculturas en contextos expositivos.

Esta interdisciplinariedad, enfrentada a una mentalidad clasificadora demasiado recelosa, les llevó incluso a protagonizar litigios memorables análogos al famoso proceso Brancusi. En el caso del gran escultor rumano, sus piezas debían pagar para entrar en los Estados Unidos como materiales industriales, al no ser reconocidas como esculturas por los "críticos" funcionarios de aduanas, incapaces de valorar la abstracción vanguardista de lo que tenían ante sus ojos. En el caso Baschet, al trasladar sus piezas para ser expuestas en la galería Waddell y en el Moma de Nueva York, se encontraron con que la ley norteamericana establecía que una obra de arte no podía tener ninguna utilidad ni aplicación, de manera que las piezas Baschet debían tributar como instrumentos musicales, o sea productos comerciales de consumo y no como obras de arte. Ante esta clasificación impositiva, Alfred Bar, director del Moma, impulsó una campaña respaldada por otros artistas e intelectuales para cambiar la ley y actualmente podemos encontrar la "Enmienda Baschet", que permite que una escultura ofrezca alguna utilidad instrumental.

\section{Participación y Accesibilidad universal en la Escultura Sonora} Baschet

El desarrollo de los primeros prototipos y modelos definitivos Baschet -algunos de ellos clasificables como esculturas, otros como instrumentos musicales- permitían que cualquiera persona pudiera hacerlos sonar sin necesidad de una aproximación técnica previa. Estos objetos sonoros experimentales, fueron expuestos como una invitación para que los visitantes pudieran hacerlos sonar. Por ello, desde muy al principio, las ESB repararon en la importancia accesibilidad, en facilitar su uso a toda persona que quisiera hacerlas sonar.

Entre sus más destacados hallazgos en la investigación de sistemas y materiales generadores de sonido y su modulación, destaca la familia de los llamados "Cristales Baschet". Esta familia, no solo integra una gama de instrumentos cromáticos y diatónicos, sino que se encuentra en el cenit de la combinación de investigación acústica y la voluntad de 
accesibilidad. El principio del Cristal, aplicado a instrumentos y esculturas, permite que cualquier persona genere un sonido puro y bien definido sin necesidad de entrenamiento técnico previo, con una gran respuesta dinámica a la acción del tacto, siendo por ello apreciado tanto por músicos especializados como por todas las personas que acceden al potencial de una acción sonora muy rica y expresiva. (Figura 2)

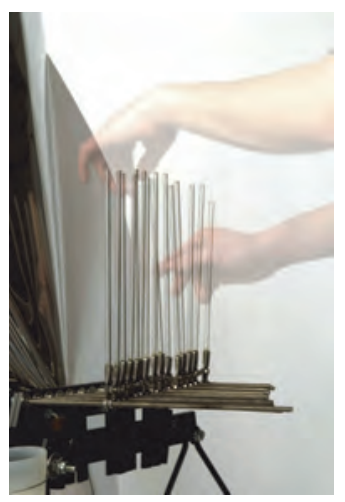

Figure 2. Detalle de las varillas de vidrio de un Cristal Trombón. Foto Vicent Matamoros, 2010.

La elección del sonido como eje de trabajo, lleva consigo un potencial de observación y contemplación implícito, así como una dimensión comunicativa que conduce la obra de los hermanos Baschet a desarrollar una especie de "filosofía de la participación". El conjunto de la ESB se basa en hacer posible que cuantas más personas tengan la oportunidad de experimentar y gozar del sonido, y a la vez plantea oportunidades para la colaboración en situaciones creativas o pedagógicas entre personas procedentes de ámbitos muy distintos. Empezando por ellos mismos: dos hermanos que trabajan en colaboración respetando sus diferencias y sumando sus capacidades, para llegar a un punto significativamente distinto de lo que producirían sus trabajos por separado. Partiendo de esta relación, sus colaboraciones se ramifican en todas direcciones, inicialmente con músicos, intérpretes y compositores, para desarrollar los primeros experimentos y las primeras muestras y conciertos como en su primera muestra en 1963 en el Musée des Arts Décoratifs de París y con exposiciones sorprendentes e interactivas cualificadas como Hands $\mathrm{On}$. Se requiere que el visitante a la exposición interactue. Las piezas tienen unas propiedades que el 
visitante puede y debe explorar, para que la obra se manifieste en su naturaleza sonora. Esta filosofía participativa diríamos que fluye huyendo del clásico concepto expositivo "se ruega no tocar" para invitar con un provocador "Please Play!"

En todo su trayecto intelectual, creativo y de producción artística, los hermanos Baschet manifiestan el propósito de generar un arte para todos los seres humanos sin excepción. Un arte del cual nadie pueda estar excluido, del cual ninguna persona por ninguna condición singular pueda dejar de disfrutar. Un arte no elitista, no "selectivo"; un arte que -visto desde los actuales logros en derechos de las personaspodríamos calificar como "arte inclusivo", flexible, que proporciona oportunidades para que cada persona pueda acceder y participar a su manera.

En algunos casos, la obra de los hermanos Baschet, se genera a partir de un propósito explícito de facilitar el acceso a la obra por parte de algún colectivo de personas con discapacidad. En este sentido hay que destacar su enorme curiosidad y su atrevimiento hacia nuevos retos. Esto les lleva en 1966 a aceptar la propuesta de David y Eléonore Hays de participar en el National Theatre for the Deaf ("Teatro Nacional para los Sordos") de Nueva York. Empezaron las experiencias con los alumnos de mecánica de la New York School for the Deaf, inventando aplicaciones para que las vibraciones sonoras pudieran ser percibidas por el oído interno de personas con daños neurológicos, con apéndices de contacto especialmente diseñados para mandar las vibraciones directamente al cráneo. Para personas con sordera profunda, diseñaron estructuras que pudieran hacer vibrar el suelo, a través de los cuales, los ritmos y las duraciones de las frecuencias mas graves pudieran ser experimentados táctilmente. Estas estructuras también pueden ser utilizadas, lógicamente, por todas las personas sin discapacidad.

Esta trayectoria inclusiva se enriquece con exposiciones masivas como la Exposición Universal de Osaka en 1970. De esta manera, con la participación de literalmente millones de personas, los Baschet contaban con la observación de posibles necesidades y estrategias para resolverlas sin menoscabar la naturaleza sonora y plástica de su obra. Paralelamente a las exposiciones, esta actitud lleva a concebir actividades de difusión de todo tipo, desde giras de conciertos a proyectos de construcción protagonizados por colectivos distintos en varios países. (Figura 3) 


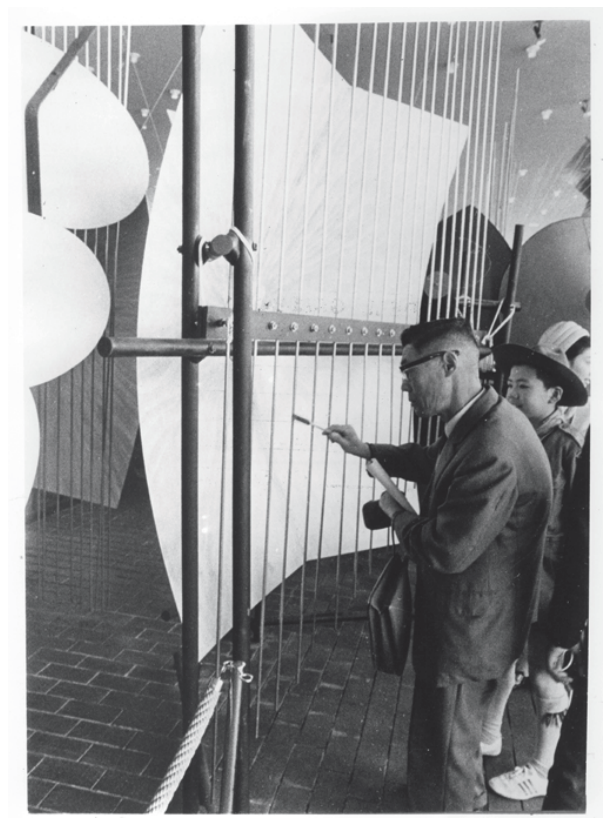

Figure 3. Osaka, 1970. Autor desconocido.

Asimismo, François Baschet, empieza a trabajar en proyectos que permitan no solo la interpretación sonora, sino que inviten a quien lo desee a tomar parte del proceso de construcción de los objetos, aprendiendo el arte de la modificación de los generadores de sonido y su disposición plástica. Publica su libro "Sound Structres" (Baschet,F. 1999, Op.cit.) y otro libro - "Klang Objekte”- sobre la construcción de fuentes, molinos y recursos sonoros activos e interactivos (Baschet, F., Villeminot, A., 1993), de carácter muy práctico, destinado a estudiantes de formación profesional. También proyecta y prueba reiteradamente prototipos de kits de autoconstrucción, una especie de mecano musical, con los que cada cual pueda experimentar con los principios acústicos en la recombinación de unos elementos básicos preestablecidos, a imagen y semejanza de los modelos escultóricos e instrumentales mayores. 


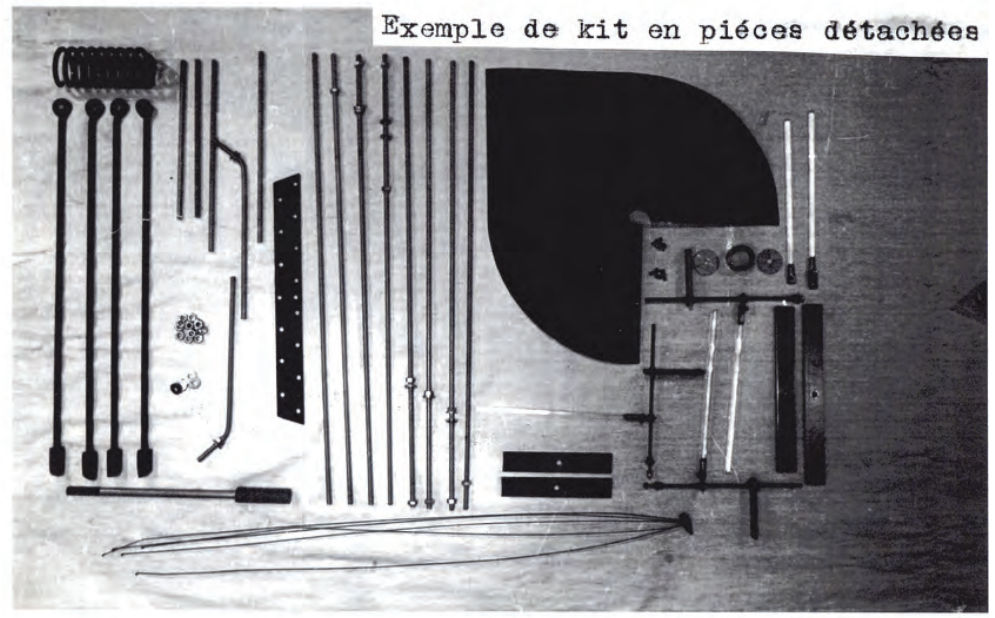

Figure 4. Ejemplo de Kit desmontado. Fotografía por catalogar. Gentileza de François Baschet.

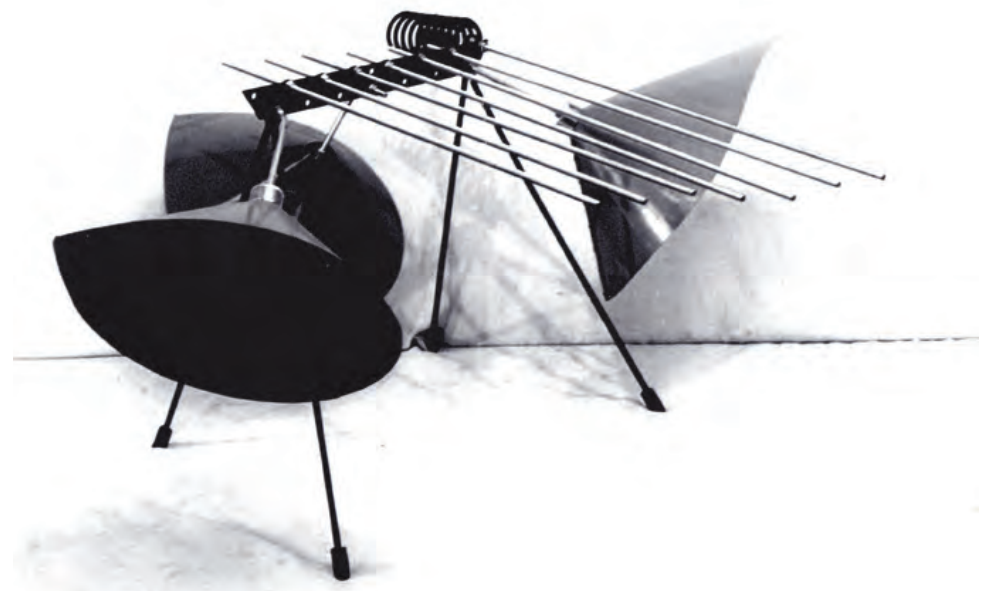

Figure 5. Ejemplo de Kit montado en una de sus posibles configuraciones. Fotografía por catalogar. Gentileza de François Baschet. 


\section{Martí Ruiz \& Robert Ruiz - Escultura Sonora Baschet}

En 1975 la fundación del Museo Guggenheim de Nueva York les propone participar en un programa educativo piloto Learning trhough the Arts, destinado a la reinserción de personas con dificultades de integración social. A partir de esta experiencia, y en colaboración con Alain Dumont y Vincent Baschet, y otros pedagogos empiezan a trabajar en el conjunto de estructuras sonoras del Instrumentarium Pedagógico Baschet (IPB). Un proceso de diseño que tardará diez años en ser considerado completado. Se trata de un conjunto de 14 piezas concebidas como una paleta sonora. Cada una está pensada para ofrecer sonidos diversos entre ellos, sin necesidad de una técnica concreta, y escapando del riesgo de que ningún prejuicio sobre las capacidades con instrumentos convencionales generen desconfianza, evitando un freno muy extendido entre quienes no se consideran músicos. Fueron diseñados para un transporte fácil y poder participar en experiencias en todo tipo de centros en varios países.

La gama de sonidos posibles está dispuesta para poder yuxtaponerse, como lo hace la música moderna, sin arreglo a una tonalidad determinada, sino por otro tipo de criterios que se pueden desarrollar trabajando directamente con los sonidos, tal como hace también la música electroacústica. El concepto fundamental que se manifiesta en el conjunto del IPB es el de favorecer el despertar musical, a través de un recurso con el que poder experimental a un nivel pre musical, para canalizar las experiencias hacia una educación de la musicalidad acorde con el propio proceso de cada uno, nunca sujeto a ideas preconcebidas. Es decir, primero la experiencia y después los conceptos y su organización.

El desarrollo de los objetos se produce en paralelo la creación una metodología pedagógica -un corpus de actividades y estrategias- que ayude a conducir la experiencia propuesta sin inhibir la intuición de cada usuario o intérprete. Las actividades buscan llegar a despertar las capacidades musicales partiendo de escuchar los sonidos que cada uno puede investigar sobre las piezas del IPB, pasando por la escucha lo que tocan otras personas, hasta la experiencia del sonar conjunto, improvisado o auto-organizado. Las condiciones que el IPB proporciona son adecuadas para todo tipo de personas de todas las edades y condiciones físicas y mentales. 
Este planteamiento supone una alternativa para todas la personas que sienten limitaciones ante las pedagogías académicas de la música, que siguen metodologías muy marcadas hacia el desarrollo de un determinado tipo de capacidades y competencias con códigos muy específicos. Cristina Vidal-Quadras de Lewin Richter ha trabajado con el IPB desde 1974 en Singapore, Hong-Kong, Melbourne, Bogotá, Sevilla y Barcelona, en varios aspectos de la enseñanza escolar musical interdisciplinaria (artes plásticas, lengua, teatro, danza y terapia). VidalQuadras declara en la página oficial de internet de François Baschet:

Siempre creí que la intuición era fuente de enseñanza creativa. Sufrí, como profesora de música, el tedio de programas de enseñanza inadaptados. En esa época de mi vida, mi trabajo de pedagoga musical me aburría. Debía conformarme a un programa arcaico, en un momento en que la expresión cultural mundial vivía una revolución general. Yo buscaba un método que incluyera la interactividad y la participación de los estudiantes. Al descubrir las estructuras sonoras Baschet, encontré las herramientas que me hacían falta.

Fue en 1974 que me encontré con Bernard Baschet en su taller. Tuve allí la ocasión de estar en contacto y de utilizar, a mi ritmo, las formas extraordinarias, los materiales y todas las vibraciones de aquellos instrumentos, de aquellas esculturas, un universo maravilloso y onírico. Al mismo tiempo, fui iniciada a los métodos terapéuticos y a la filosofía libertaria de Bernard Baschet: "No tenemos un método de trabajo". ${ }^{1}$

El aumento progresivo de la demanda por parte centros de educación especial, escuelas, institutos de acceder a las prácticas con el IPB dan lugar a la creación de la asociación Structures Sonores et Pedagogie, en 1981, dedicada a la construcción, comercialización del IPB así como de actividades de formación para educadores que pudieran aplicar y extender los métodos propuestos. Fueron convocados por la Cité de la Musique, el IRCAM o el Conservatoire National Superieur. Bernard Baschet y Romain Pomedio trabajaron con dedicación durante ocho años con chicos autistas. Magali Viallefont realizó la tesis doctoral 
Qu'apporte la practtique musical à la gestualle des handicappés. El canal de televisión franco-alemán Arte produjo Sprachloss, un documental muy significativo, precioso testimonio del trabajo con el IPB de Bernard Baschet y Pomedio.

Paralelamente a los desarrollos con el IPB, las colaboraciones de François Baschet con escuelas, institutos y centros de formación profesional han dado buenos resultado también en el Estado Español, con la experiencia de Fuentes de Madrid 88. En Cataluña con las premiadas experiencias de investigación y construcción con alumnos de Secundaria del Instituto IES Castellar de Vallès, en colaboración con el profesor de Ciencias Miquel Calvet.

Todo ello configura el rico marco de acción del conjunto de la ESB, que no se limita a lo convencionalmente asociado al arte, a la música o al diseño, sino apostando por la investigación y la pedagogía como manifestación de un pensamiento inclusivo destacable.

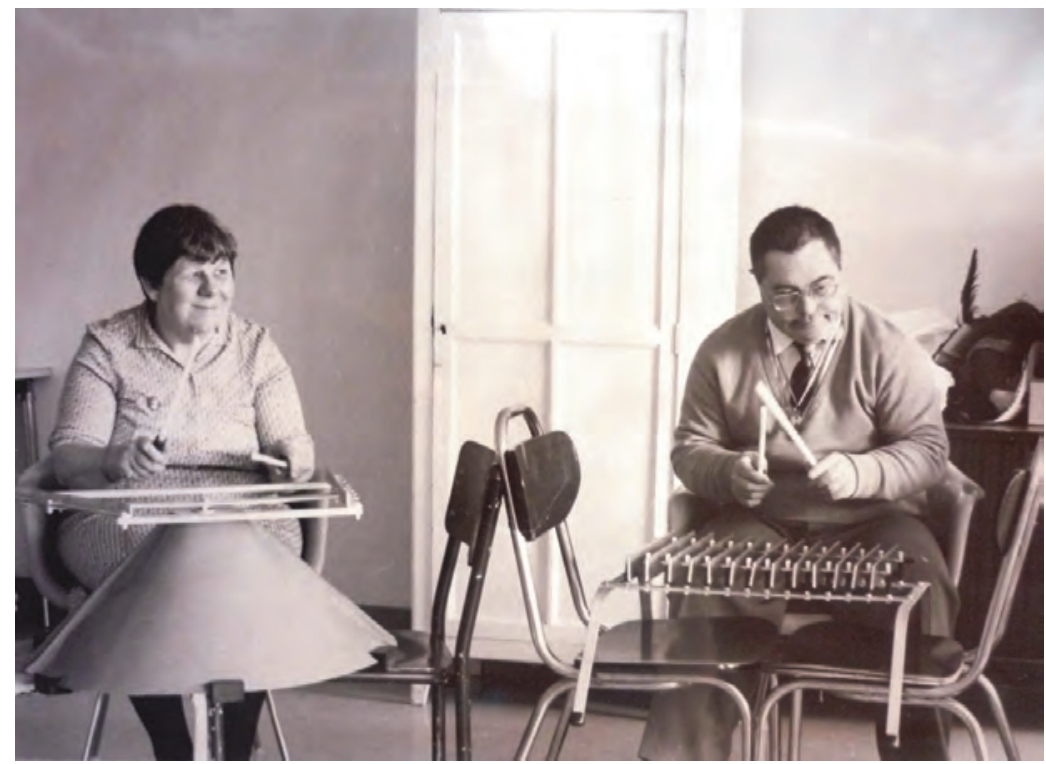

Figure 6. Foto inédita por catalogar, autor desconocido. Facilitada por Bernard Baschet y SSP, circa 1970. 


\section{Introducción a los Conceptos Básicos del Universal Design}

Conviene ahora recordar algunos de los aspectos clave del enfoque del Universal Design -Diseño Universal o Diseño para todos-, para poder efectuar un análisis como el propuesto en el presente artículo.

En linea con los avances en los derechos civiles y los grandes movimientos para acercarnos a la igualdad social en todos los terrenos durante el siglo XX, en los que la podemos incluir los posicionamientos de las hermanos Baschet, hemos querido abrir una mirada que englobe los principios de lo que se ha llamado Universal Design (UD), y que consideramos un conjunto de propuestas e intenciones valiosas, que por fortuna han ido emergiendo, tomando forma $\mathrm{y}$ ampliando sus implicaciones en cada vez mas ámbitos de acción. La intención de UD es la de dar accesibilidad al mayor número de personas sin discriminación alguna por sus condiciones y capacidades, a oportunidades para una desarrollo personal digno y equitativo.

Ron Mace, y sus colaboradores (arquitectos, diseñadores de productos, ingenieros e investigadores en diseño de entornos) definieron el Universal Design como:

El diseño de productos y entornos utilizables por todas la personas, en la mayor amplitud posible, sin la necesidad de posteriores adaptaciones o diseños especializados. (Conell et al., 1997)

En un inicio, esta perspectiva nació de la necesidad de construir edificios y espacios públicos para que fueran accesibles a las personas con discapacidad, empezando en 1973 en Carolina del Norte, y extendiéndose al resto de estados con la ley Americans with Disabilities Act de 1990: ADA, en 1990, sobre derechos de accesibilidad de estas personas a estos entornos.

Sin embargo, y lógicamente, la preocupación por el acceso de estas personas, generó entornos y edificios accesibles a personas que, sin discapacidad, hubieran podido tener dificultades para acceder a ellos por causa de otras condiciones personales. 
En el Estado Español, la Ley 51/2003 define los conceptos de «accesibilidad universal» y «diseño para todos» en los siguientes términos: ${ }^{2}$

c) Accesibilidad universal: la condición que deben cumplir los entornos, procesos, bienes, productos y servicios, así como los objetos o instrumentos, herramientas y dispositivos, para ser comprensibles, utilizables y practicables por todas las personas en condiciones de seguridad y comodidad y de la forma más autónoma y natural posible. Presupone la estrategia de «diseño para todos»y se entiende sin prejuicio de los ajustes razonables que deban adoptarse.

d) Diseño para todos: la actividad por la que se concibe o proyecta, desde el origen, y siempre que ello sea posible, entornos, procesos, bienes, productos, servicios, objetos, instrumentos, dispositivos, o herramientas, de tal forma que puedan ser utilizados por todas las personas, en la mayor extensión posible.

De esta forma la legislación española concreta una forma de asumir el UD en nuestro contexto jurídico de manera complementaria al propósito de accesibilidad universal permitiendo y propiciando los procedimientos de UD basados los iniciales principios de acción.

Tenemos pues que destacar con entusiasmo que los principios pensados inicialmente para dar mayor grado de accesibilidad en lo arquitectónico, se hayan considerado relevantes para otro tipo de diseños y servicios. En esta expansión hay un hecho contrastado ampliamente y que resulta imprescindible no pasar por alto porqué atañe a todo el mundo: Una mayor accesibilidad no solo constituye un progreso para las personas a quien va destinada originalmente la adaptación, sino que el resto de personas también pueden verse beneficiadas por ella. El camino de la inclusión y la atención a la diversidad favorece a todos en mayor o menor medida. Esto genera un marco con una voluntad no segregadora.

Estos principios han sido ampliamente difundidos desde su formulación por Ron Mace y sus colaboradores, en 1997: 
1. Uso equitativo: Lo diseñado proporciona los mismos significados para todos/das, eliminando posibles estigmatizaciones garantizando la equidad y a través de diseños atractivos para todos los/las usuarios/as.

2. Flexibilidad en el uso: Posibilidad de elección de formas de uso. 3. Uso simple e intuitivo: No implica complejidades innecesarias y ofrece retroalimentación positiva durante y después de las tareas.

4. Información perceptible: Aporta contrates entre lo esencial y lo secundario a través de información multi-modal, redundancias.

5. Tolerancia al error: lo diseñado minimiza efectos aleatorios y advierte de posibles errores.

6. Bajo esfuerzo físico: Lo diseñado ayuda a mantener posiciones adecuadas, proporciona una utilización a partir de un esfuerzo físico razonable y minimiza las acciones repetitivas y continuada.

7. Tamaño y espacio para el uso apropiado: Aporta líneas claras de visión, posición cómoda y posibilidad de atenciones individualizadas. (Conell et.al. Op.Cit)

Existen recursos para la evaluación de la medida en la que un producto, un instrumento musical, por ejemplo, se ajusta a estos siete principios; recursos pensados para la evaluación de la adecuación de productos a los siete principios del UD. Para efectuar nuestro análisis tentativo, nos basaremos en algunos aspectos propuestos por la North Carolina University como indicadores de cualidades como algunos puntos de referencia.

Las coincidencias democratizadoras entre los ideales de los Hermanos Baschet con la línea de lo propuesto inicialmente por Mace parece que confluyen en tanto que los principios del UD se extiende internacionalmente, con el paso del tiempo e implementándose en ámbitos como el Universal Instructional Design o el Universal Design for Learning. Es decir que las actividades y los recursos para el aprendizaje se plantean desde los mismos principios de UD.

El siguiente hito que debemos destacar en este proceso histórico, por las implicaciones enormes que tiene en el Estado Español, es la aparición por ley de los principios de UD en el marco de las enseñanzas universitarias. Vemos con esperanza esta ampliación del marco de 


\section{Martí Ruiz \& Robert Ruiz - Escultura Sonora Baschet}

aplicación, cómo desde las Universidades y la administración pública se quiere promover unas condiciones de igualdad de oportunidades, en todo los terrenos que sea posible. De alguna manera podemos ver en estos cambios, coetáneos de tantas otras realidades antagonistas actuales, como una línea progresista en la que se puede inscribir totalmente los principios fundamentales de ESB. I el IPB. Sería muy interesante estudiar cronológicamente la relaciones de influencias recíprocas que se hayan podido suceder entre estos movimientos de lucha contra la exclusión social, por la igualdad social, la accesibilidad universal, y las actividades llevadas a cabo por los Hermanos Baschet. A nosotros nos parece ver en ella el signo de los tiempos, hacia una sociedad cooperativa, tolerante y civilizada, que respeta la diversidad.

En este sentido, vamos a tomar el diseño y los usos del IPB para constatar hasta qué punto llega la coincidencia de criterios con el UD, dando por sentado que los hermanos Baschet empezaron sus exposiciones participativas en los años sesenta, sus actividades deliberadamente inclusivas en 1975 y el diseño del IPB no acabó hasta 1985, todo ello antes de la formulación legal impulsada por Mace en los años setenta para la arquitectura y extendida a todos los ámbitos en 1990.

\section{Algunas cualidades del Instrumentarium pedagógico Baschet, consideradas desde la perspectiva de los principios del UD}

Las 14 piezas del Instrumentarium, con las acciones y actividades que permiten, reúnen un gran potencial combinatorio que lo hace altamente accesible, facilitador de la participación de toda persona y, por tanto, posee un alto valor -a nuestro entender- para la creación de entornos inclusivos de práctica musical e inclusivo. Particularmente si se entiende este Instrumentarium no pieza a pieza sino como conjunto. Este primer ensayo analiza el conjunto, contando con las propiedades de cada pieza, pero sin entrar en detalles en términos de diseño industrial ni de las actividades que permite o no permite cada pieza por separado. (Figura 7) 


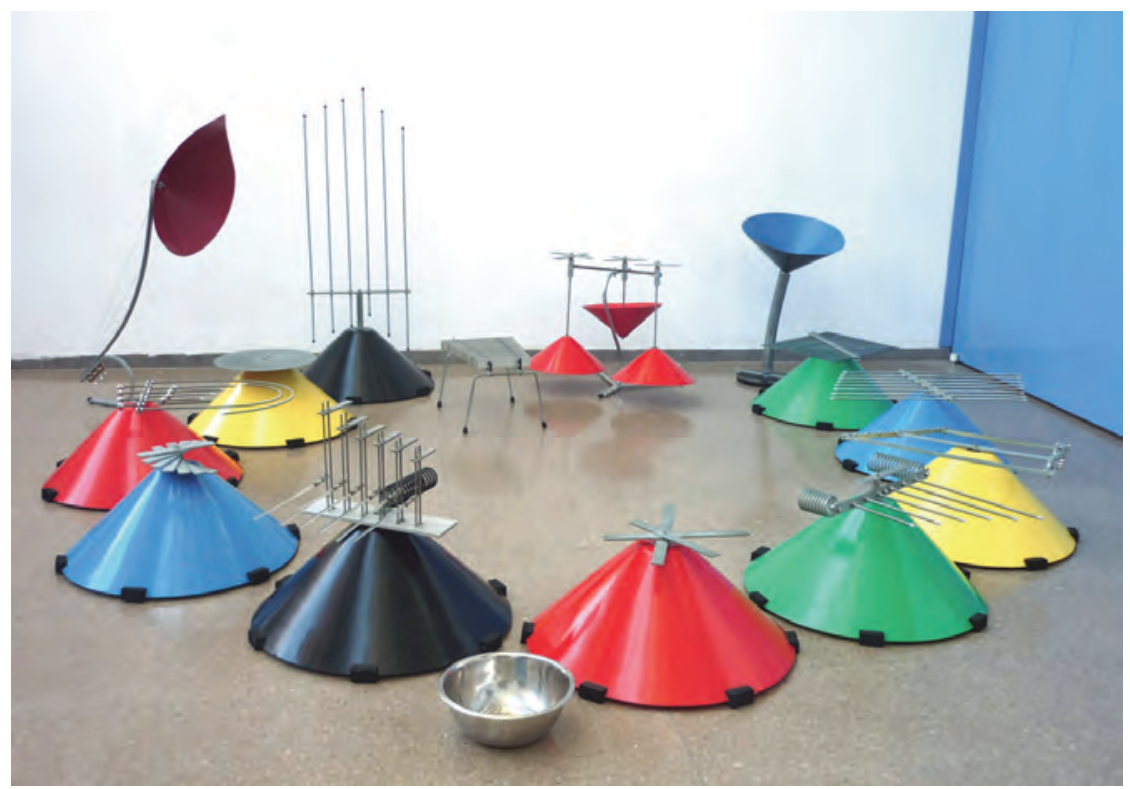

Figure 7. 14 piezas que conforman el Instrumentarium Pedagógico Baschet, gentileza de Andreu Ubach. Foto: Martí Ruiz.

Tomamos el IPB como tema de reflexión específico dentro del campo de la ESB por ser, a nuestro entender, un destacado ejemplo de propuesta inclusiva en lo que al Arte Contemporáneo se refiere. Sus concepciones respecto a la función social del arte no solo les llevaron a ser pioneros de un arte cuyo público no es un tipo de persona en concreto, sino que conciben un arte que pueda hacerse cercano y apropiado por cualquier persona, sea cual sea su bagaje cultural. Esta concepción participativa, de la escultura sonora y del arte en general podría haber quedado en este punto como un hito en esta macrotendencia hacia la interactividad, hacia la transversalidad, y lo multidisciplinario. Pero su postura radicalmente democratizadora les llevó a ahondar en las posibilidades de lo relacional al combinar las grandes exposiciones $H A N D S O N$ y las giras de conciertos, con la publicación de libros y la generación de recursos y actividades, lúdicas 


\section{Martí Ruiz \& Robert Ruiz - Escultura Sonora Baschet}

y pedagógicas, para extender y compartir sus hallazgos. De este posicionamiento llevado hasta las últimas consecuencias aparece el IPB, con una plena consciencia de sus implicaciones: Bernard Baschet asegura que en cuanto empezaron a trabajar cada vez más en su dimensión pedagógica e inclusiva, sabían que determinados ambientes y grupos de galeristas, coleccionistas y críticos dejarían de interesarse y de darles repercusión mediática, pero que aun así sabían que valía la pena. En parte fue así. A nuestro juicio, el gran reconocimiento internacional todavía no ha llegado. Pero como intuían los hermanos Baschet desde el principio de su compleja, expansiva y paciente carrera artística, hoy en día nuevas generaciones reconsideran la función social del arte, las relaciones entre arte y ciencia, y tanto las ESB como el IPB cada vez son más conocidos.

Como hemos visto, el proceso de diseño y adecuación del IPB duró prácticamente diez años, de 1975 a 1983. Durante este proceso se buscaron una formas y disposiciones singulares, configuraciones distintas de las utilizadas en el resto de la ESB. Los principios acústicos Baschet para obtener distintas sonoridades con un grupo limitado de materiales y formas físicas, se ponen al servicio de unos condicionantes de accesibilidad, resistencia y simplicidad.

El espíritu investigador y lúdico de los Hermanos Baschet se había podido transmitir a millones de personas que asistían a sus exposiciones y descubrían el sonido de sus Esculturas. El IPB nació para conectar con la curiosidad habitualmente característica de la infancia. Admirados al ver como algunos principios de la pintura abstracta habían sido extendidamente asimilados en la educación plástica infantil, disponiendo las herramientas para experimentar con libertad. Los Baschet entendieron que su vocación participativa debía aprovechar esta apertura pedagógica para una propuesta de calado menos anecdótico que una exposición. Fundir el juego y el descubrimiento de unos sonidos con una pedagogía activa, que permitiera a cada persona tomar consciencia de sus capacidades y de las posibilidades del sonido a partir de sus propias experiencias. En Palabras de Bernard Baschet: "Hemos querido poner colores sonoros a disposición de los niños y darles libertad de tocar sin reproducir." (Baschet, B., 1988, citado por Bousquet, F. y Ubach, A., 2008, p.133) 
El conjunto del IPB pensado para dar acceso a los niños, con el tiempo se ha demostrado absolutamente apropiado para cualquier otra franja de edad. Por ello, podríamos considerar que la su accesibilidad fomenta situaciones inclusivas, con grupos de participantes o usuarios con capacidades y características muy dispares. "...éste permite responder a las expectativas de usuarios diferentes, desde la primera infancia a las personas de mayor edad, pasando por los adolescentes y los adultos, con diferentes niveles de estructuración personal, y en el seno de diversas instituciones". (Baschet, B., 1988, citado por Bousquet, F. y Ubach, A. p.133) Así como el trabajo con "Medios especializados, personas con necesidades educativas especiales"(Baschet, B., 1988, citado por Bousquet, F. y Ubach, A. p.142)

La amplia accesibilidad y sus atractivas cualidades le confieren un alto grado de capacidad de facilitar la participación de todos/as, con actividades que hoy en día podríamos llamar "multinivel". Esta particularidad hace del Instrumentarium un conjunto muy abierto. Lejos de ser un recurso especialmente diseñado para personas con discapacidad, que quizá podría tener un uso en una contexto segregado, se muestra como un conjunto verdaderamente inclusivo, siguiendo la estela de la experiencia de las exposiciones de participativas HANDS ON con "Públicos heterogéneos". (Bousquet, F., Ubach, A., Op.cit., p.143)

Esta línea de pensamiento, de permanente replanteamiento de las posibilidades, como hemos mencionado, se manifiesta tanto en las características formales del IPB como en la metodología propuesta por la SSP en una "sucesión de actividades renovadas constantemente descubrimiento, exploración, producción, composición, codificación e interpretación-..." (Bousquet, F., Ubach, A., Op.cit., p.139)

La intención de propiciar el despertar de las capacidades musicales, puede dar paso a otros aprendizajes interpretativos, juegos interdisciplinarios y de educación de la escucha. Así lo atestigua la notable suma de instituciones enumeradas por F. Bousquet, colaborador de los Hermanos Baschet, formador y actual constructor del IPB: más de 500 instituciones educativas, de carácter asistencial, musicales, etc., han adquirido el IPB. ${ }^{3}$ Actualmente la SSP continua realizando las formaciones para el uso del IPB y mantiene contacto con todas las instituciones y particulares que lo usan. 
El conjunto está pensado como la suma de texturas sonoras, de posibilidades de modulación del sonido. Todos los generadores de vibraciones son metálicos. La mayoría de piezas cuentan con un un difusor en forma de cono de fibra y resina, o de cartón rígido, muy resistentes, de colores vivos y contrastados.

Para quienes no hayan podido escuchar y tocar el IPB, describimos brevemente cada una de las piezas.

1. Estrella: Tres láminas horizontales colladas asimétricamente generan seis longitudes vibrantes que producen sonidos llenos no muy largos, con ataque definido. (Figura 8)

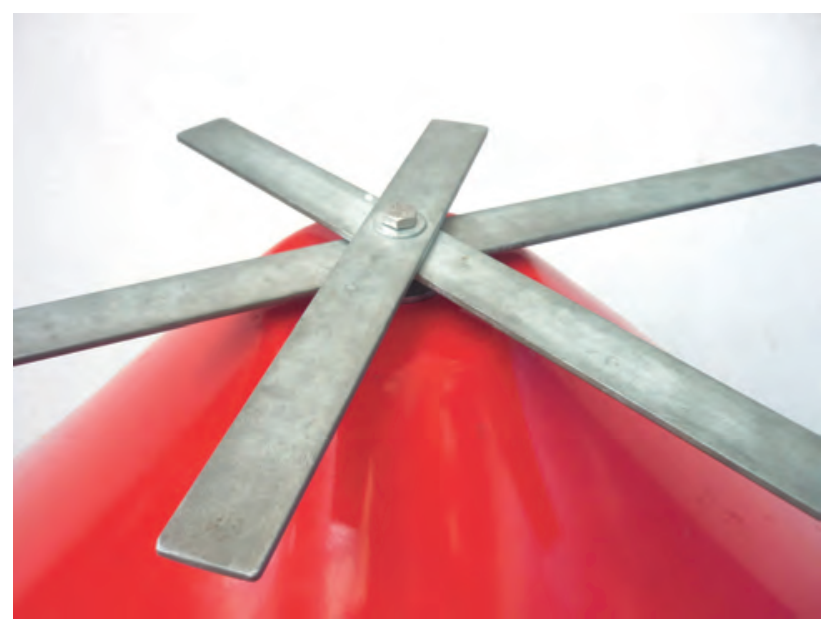

Figura 8. Detalle de Estrella. Foto Martí Ruiz. Pueden escuchar una muestra en http://www.structuresonore.eu/tabid/66/Default.aspx

2. Disco: Un disco metálico relativamente flexible, dispuesto en horizontal, collado asimétricamente. Puede generar sonido largos y profundos como un gong. Permite la modulación en altura de los sonidos al tensionar y doblar el disco. ${ }^{4}$

3. Candelabro: Seis barras largas dispuestas en vertical generan sonidos largos y complejos, un poco como campanas. Los extremos cortos del 
las barras, que sobresalen por debajo del puente producen seis sonidos más cortos -pero profundamente reverberados por simpatía- de alturas muy distintas. ${ }^{5}$

4. Doble Muelle: Teclado multitímbrico horizontal compuesto por 6 barras corta de diferentes longitudes, y una lámina collada asimétricamente formando dos longitudes vibrantes de sonidos cortos, conectadas a dos muelles que pueden ser percutidos, o vibrar libremente para añadir reverberación al resto de sonidos. Se puede parar la vibración de los muelles y constatar táctilmente la acumulación de energía acústica en las reverberaciones de muelles. ${ }^{6}$ (Figura 9)

Figure 9. Detalle de Dos Muelles. Foto Martí Ruiz.

5. Barras curvas: Teclado multitímbrico horizontal compuesto por dos barras largas curvadas que generas sonidos largos, junto con otras 8 barras cortas de diferentes longitudes -4 con pesos en los extremos y 4 en puntos nodales- generan sonidos complejos con ataques reverberados por la simpatía del conjunto. ${ }^{7}$ 
6. Barras rectas: Teclado horizontal compuesto por 8 barras de longitud media, dispuestas para producir sonidos de diferente altura moderadamente reverberados. ${ }^{8}$

7. Escalera: Seis láminas de longitudes decrecientes, colladas en espiral simétrica, ofrece dos teclados helicoidales iguales, de sonidos densos, llenos de frecuencias medias, con ataques notables y una resonancia corta. ${ }^{9}$ (Figura 10)

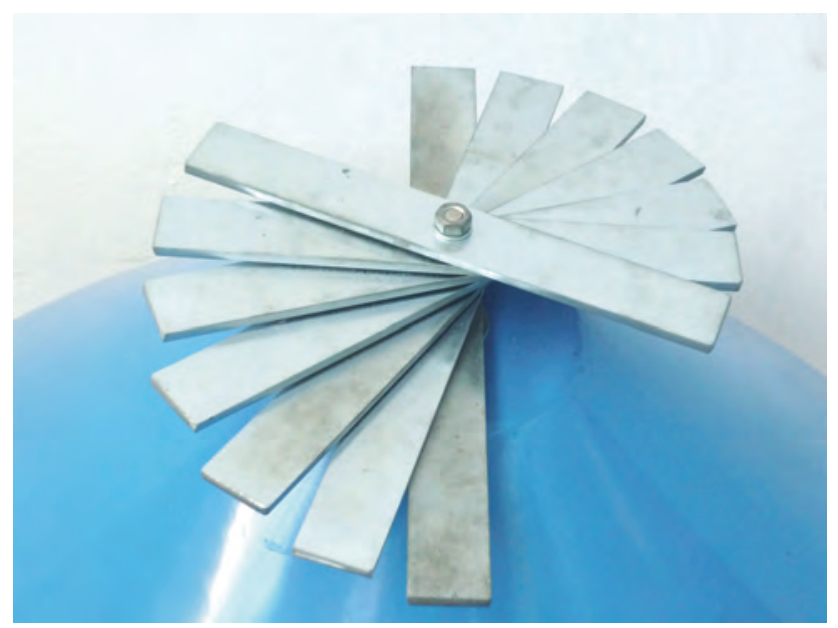

Figure 10. Detalle de Escalera.

8. Cuerdas: Sistema semejante al arpa o salterio horizontal de 8 cuerdas metálicas, reverberadas por simpatía, con ataque variable según el percutor, plectro o dedos, afinable, con capacidad para "vibratos" al tensar el marco puente. Ofrece sonidos largos, brillantes y limpios. ${ }^{10}$ 9. Arco: 3 cuerdas metálicas fijadas a un arco flexible que se pueden tocar como un arpa, como un berimbau o frotando con un arco. De todos modos produce sonidos largos, muy sensibles a la tensión variable que se puede aplicar al arco para cambiar la altura de notas con orgánicos glissandi. ${ }^{11}$ 
10. Parilla: 25 barritas finas de metal horizontales, con pequeñas diferencias de longitudes reparten el ascenso o descenso de la frecuencias en pequeñas fracciones. Cada sonido se enriquece por la reverberación del conjunto. ${ }^{12}$

11. Muelle: Un muelle largo muy flexible y una lámina en la base, sonando a través de un cono de cartón suspendido en el extremo. El sonido del muelle largo y reverberado se puede detener al tacto. La lámina de sonido corto suena reverberada a través del muelle. Ofrece una gran variedad de sonidos en función de la forma de hacerlo sonar -percutiéndolo o frotándolo con las manos, con baquetas de distintos materiales, etc-. Añade el factor de la movilidad, dado que la base es muy pesada y el extremo del muelle con el cono puede bascular y girar libremente, desplazando ostensiblemente la direccionalidad del sonido. ${ }^{13}$

12. Silvante: 13 láminas de dural de longitudes decrecientes, suspendidas para vibrar libremente al ser estimuladas por el extremo estrecho, produciendo sonidos brillantes de altísima frecuencia y notable longitud. No necesitan cono difusor. ${ }^{14}$

13. Tres Cruces: Tres pares de láminas en cruz, conectados cada uno a un difusor independiente, ofrece los sonidos mas secos y cortos del conjunto. ${ }^{15}$

14. Cristal: Seis varillas de vidrio encastadas al sistema de doble barra metálica del Cristal Baschet. Obtenemos sonidos largos y limpios, sin ataque, gran rango dinámico en función de la intensidad de la presión al frotar las varillas con los dedos mojados. Los sonidos son reverberados simpáticamente por el conjunto y por un muelle, que puede ser percutido, así como los contrapesos del sistema metálico. Afinación determinable y muy estable. ${ }^{16}$

Una vez descritas las principales características del Instrumentarium Baschet vamos a examinarlo, considerando sus características en base a los siete principios de UD.

\section{Uso equitativo}

El conjunto está pensado para ser usado musicalmente, y para facilitar situaciones de aprendizaje, de sensibilización. Desde usos extremadamente básicos, facilita evoluciones y desarrollos interpretativos más sofisticados a los que se puede ir accediendo. 
El conjunto facilita usos puramente lúdicos, escénicos, y de aprendizaje del sonar y de las características de objeto sonoro. Desde el punto de vista constructivo, muestran los principios acústicos con esquemática claridad y facilitan la comprensión de los acontecimientos acústicos.

La gran variedad tímbrica y de tipos de acciones a realizar, abre muchas posibilidades entre las que elegir, siendo muy fácil, por contraste, que al menos alguna de las piezas y sus sonidos resulten atractivos para aproximarse y disponerse a interactuar.

\section{Flexibilidad en el uso}

Puede usarse de acuerdo con las condiciones ideadas y ampliamente investigadas por la SSP y todos sus usuarios, y también de cualquier otro modo. Como objetos sonoros, cada uno de ellos, e incrementando sus potenciales al añadir piezas hasta el conjunto de 14, manifiestan su potencial ante cualquier interacción táctil.

"Se pueden tocar con las manos y también con la ayuda de diversos mediadores (percutor, pelota, pincel, cepillo, hoja...)" (Bousquet, F., Ubach, A., Op.cit., p.130)

Algunas de las piezas se pueden afinar de acuerdo con criterios tonales y de textura, se pueden modificar algunas sonoridades tapando las partes generadoras de la vibración con ropas, añadiendo objetos entre las cuerdas, encima de las barras y láminas, deslizando a lo largo de las cuerdas, y en función de las dimensiones y el materiales de elemento percutor utilizado.

\section{Uso simple e intuitivo}

Todos los elementos utilizados son esenciales e imprescindibles.

No requiere ninguna instrucción determinada para usarlos. Una persona o grupo de personas que no fueran introducidas por las actividades propuestas habitualmente, rápidamente haría su lectura de los elementos dando también resultados personales, que al fin y al cabo es para lo que fueron ideadas.

El uso puede ser especialmente simple por sonar al mas mínimo contacto, con una gran sensibilidad dinámica. El conjunto precisamente busca motivar esa interacción intuitiva, que conduzca a cada usuario a su propio uso según el contexto. La metodología propuesta por la SSP así como toda la filosofía de la participación de la ESB buscan 
amplificar esta aproximación, accesibilidad, a la intuición musical.

La no-correspondencia formal con instrumentos de música conocidos así como la accesibilidad directa al mundo sonoro permiten una desinhibición rápida en el participante, que accede a una expresión sonora directa a través del instrumento.

(Bousquet, F., Ubach, A., Op.cit., p.131)

El sonido rico y claro del Cristal se produce fácilmente, cualquier persona que tenga un mínimo de capacidad motriz, puede generar esos sonidos imposibles de conseguir con ningún otro instrumento acústico. Esto es interesante tanto para músicos especializados, para maestros, para cualquier tipo de estudiante o intérprete usuario, con o sin discapacidad. Los principios de las percusiones, las cuerdas, están dispuestos meditadamente para tener el mismo potencial inclusivo.

La variedad de formas y disposiciones de los elementos generadores del sonido posibilita el uso de una amplia variedad de gestos y, "Así, la variedad de gestos inducidos por los teclados favorece el desarrollo psicomotor: horizontal, vertical, curva, circular, eje central, organización continua o particular". (Bousquet, F., Ubach, A., Op.cit., p.133)

Todas las formas cumplen con una función acústica o estructural. No hay ningún elemento añadido para decorar. Todos los sistemas que requieren un difusor, utilizan los conos de fibra como soporte; el Muelle, necesita un soporte pesado para permitir la movilidad del cono, las láminas suspendidas del Silvante requieren solamente de unas patas que las sostengan para vibrar libremente.

Son elementos eminentemente interactuadores, una muestra de unos cuantos principios básicos, siempre listos para la interacción, suenan sea cual sea la aproximación que se realice. Como objetos sonoros intrigantes, particularmente dispuestos, abren sus posibilidades con una claridad total. Son un punto de partida.

\section{Información perceptible}

Las formas simples, reducidas a lo esencial, resultan visualmente llamativas por su diversidad, sus diseños y colores contrastantes, geometrías rectas y curvas, abstractas, y todas ellas funcionales. Las 


\section{Martí Ruiz \& Robert Ruiz - Escultura Sonora Baschet}

dimensiones de cada pieza le dan presencia perceptible, abarcable al tacto con una escala de proximidad y confianza. Incluso en el caso de no poder verlos, las formas, las texturas y las disposiciones de los elementos es accesible y comprensible.

La resistencia de los conos permite también experimentar la vibración táctilmente, tanto si se trata de un usuario con alguna, mucha o ninguna deficiencia auditiva.

\section{Tolerancia al error}

Todos los elementos vibrantes están dispuestos para ser accesibles y sonar con cualquier interacción física con ellos. No hay otra cosa que hacer con las estructuras que ponerlas en funcionamiento. La metodología propuesta -des de la apretura a la escucha y los usos, La observación del fenómeno sonoro, la participación de el mismo- hacen que la idea misma de error no quepa. En algunos usos musicales de interpretación preacordada, y en caso de la libre improvisación colectiva, simple pueden producirse fenómenos o juicios estéticos que uno pueda considerar como un error, eso pertenece al dominio de la música y sus prácticas de ensayo o interpretación, pero no porque el IPB pueda usarse erróneamente. Las funciones acústicas son inmediatas, y no cabe la posibilidad de un uso sin resultados, como sí podría pasar por ejemplo manejando erróneamente una cámara de fotos, de manera que no consigamos captar el aspecto de lo que fuere.

Solamente en el caso Cristal puede suceder que se intente tocar con las manos secas, eso difícilmente produciría ningún efecto. Aun sí, si se dispone un recipiente con agua cerca del Cristal, hay un altísimo número de posibilidades, en función de las capacidades intelectivas del usuario, de hacer sonar el Cristal sin ninguna indicación.

Las partes metálicas no están pintadas ni modificadas, de manera que su tacto y temperatura indican su rigidez. Todos los cantos están redondeados y los extremos de las barras cubiertos por tapones de plástico redondos.

Es poco probable que un usuario se haga daño con el uso o el mal uso. Las varillas de cristales, tienen una resistencia elástica gracias a la lámina acerada que la sostiene, de manera que puede resistir tirones fuertes y golpes. Aún así, es cierto que para cada usuario cabe observar que si hay que tomar alguna precaución por seguridad con respecto al Cristal. 
Si se sigue una introducción guiada, se consigue progresivamente que la toma de contacto con las distintas características de los materiales facilite la formación de una consciencia las posibilidades y los riesgos de cada pieza. Así, con el uso, se descubre el umbral de intensidad con que se puede golpear o frotar una estructura, una información sobre la presión que va unida su consecuente manifestación sonora.

\section{Bajo esfuerzo físico}

Todas las estructuras, decíamos, se pueden usar con un esfuerzo mínimo. Cualquier pequeño gesto aplicado suena, pudiendo trabajar con intensidades débiles, de movimientos y resultados sutiles.

No hay necesidad de hacer esfuerzos. En función de limitaciones de movilidad se puede usar una u otra estructura, y el tamaño de las piezas facilita levantarlas o inclinarlas si es necesario para facilitar una postura cómoda, relajada, que no requiera gestos fatigantes. Se pueden utilizar elementos percutores blandos o ligeros, o tocar con las manos.

\section{Tamaño y espacio para el uso apropiado}

"Están concebidas para ser fácilmente almacenables, desmontables y transportables" (Bousquet, F., Ubach, A., Op.cit., p.130)

Una vez montados, sigue tratándose de un conjunto móvil así que se puede disponer cada pieza como sea mas conveniente, para ser usados en disposiciones personalizadas. Se pueden alzar sobre bancos, cubos o cajas. Pueden ser usados por varias personas a la vez. Los elementos generadores de sonido están dispuestos para ser accesibles en varias posiciones, sentados o tumbados, y en casi todos los casos desde los 360 grados. No hay piezas pequeñas. Las varillas de vidrio están suficientemente separadas como para frotarlas agarrándolas con la mano entera, e incluso frotando con otra parte del cuerpo.

\section{Conclusiones}

Después de esta lectura y reflexión, constatamos que podemos recopilar $\mathrm{y}$ extraer algunas conclusiones, exponer nuevas perspectivas e interrogantes, tanto a nivel pedagógico, constructivo y artístico.

Consideramos muy adecuada esta doble lectura porque permite presentar la ESB y el UD, como dos caminos cruzados, o dos manifestaciones o facetas de unos mismos principios democratizadores 


\section{Martí Ruiz \& Robert Ruiz - Escultura Sonora Baschet}

igualitarios, de atención a la diversidad, que permiten vislumbrar un horizonte prometedor y que se pueden retroalimentar mutuamente.

Constatamos la posibilidad de aplicar exitosamente -como en el caso Baschet, avant la letre- los principios del UD al terreno de los instrumentos musicales, y de otras propuestas interactivas. Constatamos también que se pueden generar condiciones de aprendizaje estimulantes, eficaces y atractivas, desde el arte, desde lo lúdico, personalizables e inclusivas.

La experiencias acumuladas por la historia del IPB constituyen un referente vivo y vívido en lo que refiere a integración social. Podemos aprender de estas iniciativas para enriquecer el resto de campos de la actividad humana en las que haya que implantar o ampliar la inclusividad, la accesibilidad universal.

Consideramos que en gran medida, el IPB cumple con los siete principios del UD. Aunque no se diseñó siguiendo todos sus los parámetros, por imposibilidad cronológica, en términos generales sí cumple con los siete principios por la mera naturaleza del proyecto que representa. Siendo esto así, nos preguntamos, si sería necesario mejorar algunos aspectos del IPB para cumplir completamente con todos los parámetros de los siete principios del UD.

Consideramos la conveniencia de impulsar nuevos estudios. Valdría la pena realizar una serie de estudios pormenorizados evaluando una por una las piezas del IPB, y exponer a Bernard Baschet y la SSP, los resultados, con propuestas concretas que pudieran aumentar el valor educativo en el UD. Estos estudios, deberían abarcar los desarrollos en la pedagogía del arte y estudiar el impacto social, para poder modificar o ampliar aspectos físicos de las piezas, de su uso y metodologías.

Para ello, sería muy interesante poder estudiar los informes de las experiencias que la SSP viene realizando desde el inicio de sus actividades, como por ejemplo las memorias redactadas por Cristina Vidal-Quadras de Lewin Richter. Sería óptimo coordinar esos estudios internacionalmente, en colaboración con universidades e instituciones especializadas en los diversos ámbitos puestos en juego en el IPB y obviamente con la misma SSP.

Al mismo tiempo, entendemos que muchos de estos principios se podrían ver como unas directrices paralelas, sensiblemente sugerentes para la utilización del IPB. 
En lo que atañe a la posibilidad actual de creación de nuevas estructuras sonoras, -y desde el conocimiento de los recursos usados por Baschet que nos aporta la tesis doctoral en curso por Martí Ruiz "Escultura Sonora Baschet: archivo documental, clasificación de aplicaciones para el desarrollo de formas acústicas"-, humildemente nos podríamos plantear añadir algunas estructuras nuevas al IPB, como proyecto a pensar desde los principios del UD:

Diseñar alguna estructura de planchas resonadoras para enriquecer el uso de la voz con el conjunto del IBP, en la línea de la familia instrumental de la Tôle à Voix Baschet. Esta idea surge de la misma noticia del uso de una de estas Tôle à Voix durante las actividades con el IPB, en el taller de Bernard Baschet, sede de la SSP. Dada las características de estas planchas metálicas, haría falta estudiar su modificación para adaptarse al UD plenamente, y reducir su hipotética peligrosidad y optimizar su accesibilidad y manejabilidad.

Podría concebirse algún nuevo elemento incluso de carácter portátil? Actualmente, en el Taller de Escultura Sonora Baschet de la UB, con colaboradores de François Baschet, Jordi Casadevall y Andreu Ubach, entre otros, estamos trabajando en aplicaciones portátiles de los principios Baschet, prototipos inéditos en la historia de la ESB. Además del entusiasmo de François ante el éxito de la aplicación de los principios para nuevas finalidades, constatamos que son muy atractivos para todos los públicos, notablemente manejables, especialmente para niños. ¿Cabría pues la posibilidad de diseñar algunas de estas estructuras para añadir el factor de la movilidad, para enriquecer el trabajo de la espacialidad y el movimiento para los usuarios del IPB, y las nociones de plurifocalidad, tan llamativamente desarrolladas por Llorenç Barber?

Constatamos además, desde el punto de vista de la aprendizaje de la organología y las actividades de construcción, que en el sentido de la transmisión del saber, -del aprendizaje de lo técnico, lo funcional, lo constructivo-, acumulado por los Baschet, el IPB y el conjunto de la ESB- muestra los principios acústicos con una claridad meridiana: enseña, descubre el enfoque de las funciones acústicas del objeto sonoro, descifra el enfoque teórico y aplicado tan característico de Baschet. El IPB no solo sirve para los usos para los que fue pensado, sino que muestra su enfoque de acústica modular que define cualquier 


\section{Marti Ruiz \& Robert Ruiz - Escultura Sonora Baschet}

instrumento: define los tipos de elementos que pueden entrar en vibración, las distintas formas de generar esa vibración, las distintas maneras de alterar estas vibraciones -modularlas en frecuencia, intensidad, expresividad-, y las distintas formas de hacerlas audibles: empezando por de la misma superficie del objeto idiofónico, hasta las sofisticadas formas de transmisión de la vibración hasta pabellones o formas capaces de amplificar y difundir esa vibración al aire o a un medio resonante.

Es cierto que el IPB no recoge todas esas posibilidades imaginables. Solamente utiliza las combinaciones que consideraron mas apropiadas para sus intenciones. Precisamente es esta concepción Baschet de las funciones acústicas, lo que nos facilita imaginar el conjunto de esas posibilidades de construcción e interacción en sus ilimitadas variaciones. Se trata del camino mismo, de la evolución de los objetos sonoros acústicos, desde su prehistórico atávico inicio, perpetuando y redefiniendo las concepciones teóricas, a menudo preservadas por unos pocos. Desde la ESB, y claramente desde el IBP, se da acceso a un gran público que históricamente no ha tenido la ocasión de usar y comprender el uso de las estructuras acústicas, de un modo también nuevo, hospitalario y libre. Y especialmente, por esta diversidad de personas que pueden usar el IPB, mayor es la concienciación hacia la necesidad y lo oportuno de incrementar la accesibilidad, la inclusividad de los soportes, instrumentos y estrategias de comunicación y creación.

Podemos repensar el IBP, podemos repensar otros instrumentos ya existentes, y podemos inventar otros nuevos. Desde el IPB, la información sobre la acústica nos llega inseparable de sus formas de uso, y remarcan un camino hacia otras configuraciones facilitadoras, en función de los pasos que queramos hacer como sociedad cultural.

Y entendemos que cuantas más oportunidades se brinden a colectivos más diversos, mayor será la diversidad resultante de enfoques y aportaciones. Se trata de la comunicación una serie de propósitos y de unos lenguajes -los técnicos constructivos y los lenguajes sonoros nacidos del uso del IPB- que se pueden comprender desde cualquier cultura local, por lo que la sinergia intercultural podría avanzar por caminos empíricos contrastables, sin renunciar a la comunicación noverbal. 
Para terminar, des del punto de vista de la pedagogía de las artes, constatamos la conveniencia de utilizar algunos principios de evaluación objetivables. Desde el punto de vista del Laboratori d'Art Sonor, consideramos favorablemente la posibilidad de usar los propósitos y los parámetros del UD -y su extensión en el UDL, Universal design for Learning-, en nuestra programación docente, en el diseño de nuestros proyectos e investigaciones de construcción. Esto nos da la oportunidad de atender a parámetros clave para estructurar y poner en valor la variadísima cantidad de observaciones a realizar con respecto al uso y los aprendizajes posibles a través del conjunto de la ESB.

En el ámbito de lo creativo abundan intangibles que no necesitan de ninguna evaluación, pero en el ámbito de la pedagogía del arte, entendemos que hoy en día, una postura comunicativa cuanto más inclusiva y multinivel posible sería deseable -especialmente cuando se trate de propuestas interactivas- para no perpetuar la fractura entre artes cultas y artes populares, así como ayudar a acercar el mundo de la cultura y el de la educación.

Con estos principios y criterios en mente, podemos mantener cierto rigor metodológico entorno del ámbito de la intuición y la creatividad, herramientas para la reflexión y la investigación. Desde este punto entendemos que podemos contribuir a una mejora en la calidad de vida culturalmente y favorecer el impacto de las sinergias arte-ciencia en la sociedad.

\section{Notas}

1 (Vidal-Quadras de Lewin Ritcher, C. «Esculturas sonoras Baschet: Cuerpo, Espíritu, Sonido» http://francois.baschet.free.fr/vidal_quadrases.html).

2 (letras c y d del artículo 2 de dicha ley, que encontraran en el Boletín Oficial del Estado http://www.boe.es/boe/dias/2003/12/03/pdfs/A43187-43195.pdf)

3 (http://www.structuresonore.eu)

4 Pueden escuchar una muestra en http://www.structuresonore.eu/tabid/69/Default.aspx

$5 \mathrm{http}: / /$ www.structuresonore.eu/tabid/66/Default.aspx

$6 \mathrm{http}: / / \mathrm{ww} w$. structuresonore.eu/tabid/70/Default.aspx

$7 \mathrm{http}: / / \mathrm{ww} w$. structuresonore.eu/tabid/76/Default.aspx

$8 \mathrm{http}: / /$ www.structuresonore.eu/tabid/77/Default.aspx

$9 \mathrm{http}: / /$ www.structuresonore.eu/tabid/71/Default.aspx 
10 http://www.structuresonore.eu/tabid/67/Default.aspx

11 http://www.structuresonore.eu/tabid/65/Default.aspx

12 http://www.structuresonore.eu/tabid/73/Default.aspx

13 http://www.structuresonore.eu/tabid/74/Default.aspx

14 http://www.structuresonore.eu/tabid/75/Default.aspx

15 http://www.structuresonore.eu/tabid/64/Default.aspx

16 http://www.structuresonore.eu/tabid/68/Default.aspx

Pueden leer más acerca de las características, historia y usos del IPB en

http:/www.er.uqam.ca/nobel/baschet/introduction/index.html

\section{Referencias}

Baschet, B. (1988). L'eveil musical de tout petit. Cahier du CENAM.

París, Edition Centre national d'action musicale.

Baschet, F. (1999). Les Structures Sonores, The Sound Sculptures of

Bernard and François Baschet, Chelmsford, UK, Soundworld

Publishers.

Baschet, F., Villeminot, A. (1993). Klang Objekte. Starnberg, Eberwald. Bousquet, F., Ubach, A. (2008). Sensibilización Musical con Estructuras

Sonoras Baschet. Aproximación a una metodología para el uso continuado del Instrumentarium Baschet en la Escuela Primaria.

Ministerio de Educación, Política Social y Deporte, Secretaría de

Estado de Educación y Formación. Edita Secretaría General

Técnica, Subdirección General de Información y Publicaciones.

Dentro de AA.DD. La competencia artística: Creatividad y apreciación

crítica. (2008). Ministerio de Educación, Política Social y

Deporte, Secretaría de Estado de Educación y Formación. Edita

Secretaría General Técnica, Subdirección General de

Información y Publicaciones.

Conell, B. R., Jones, M., Mac, R., Mueller, J., Mullick, A., Ostroff, E. et al. (1997). The Principles of Universal Design. U.S, The National Institute on Disability and Rehabilitation Research.

Department of Education. NC State University, The Center for Universal Design.

Schaeffer, P. (1966). Traité des Objets Musicaux (versión abrégée)

Editions de Seuil. Trad. del francés Araceli Cabezón de Diego. 
Madrid, Alianza Editorial (Alianza Música), (1998).

Martí Ruiz es Doctorando, Becario de investigación de la Universitat de Barcelona y Profesor de la Universitat de Vic.

Robert Ruiz es Dr. en Psicología y Profesor Titular en la Universitat de Vic.

Contact Address: Carrer Sagrada Família, 7. 08500 Vic, Barcelona. España. Email: gibrel18@gmail.com,robert.ruiz@uvic.cat 